\title{
What about the others: differential diagnosis of COVID-19 in a German emergency department
}

\author{
David Fistera ${ }^{1,2^{*}} \mathbb{C}$, Annalena Härtl' ${ }^{1}$, Dirk Pabst ${ }^{1}$, Randi Manegold ${ }^{1}$, Carola Holzner ${ }^{1}$, Christian Taube ${ }^{2}$, \\ Sebastian Dolff ${ }^{3}$, Benedikt Michael Schaarschmidt ${ }^{4}$, Lale Umutlu ${ }^{4}$, Clemens Kill ${ }^{1}$ and Joachim Risse ${ }^{1}$
}

\begin{abstract}
Background: The ongoing COVID-19 pandemic remains a major challenge for worldwide health care systems and in particular emergency medicine. An early and safe triage in the emergency department (ED) is especially crucial for proper therapy. Clinical symptoms of COVID-19 comprise those of many common diseases; thus, differential diagnosis remains challenging.
\end{abstract}

Method: We performed a retrospective study of 314 ED patients presenting with conceivable COVID-19 symptoms during the first wave in Germany. All were tested for COVID-19 with SARS-Cov-2-nasopharyngeal swabs. Forty-seven patients were positive. We analyzed the 267 COVID-19 negative patients for their main diagnosis and compared COVID-19 patients with COVID-19 negative respiratory infections for differences in laboratory parameters, symptoms, and vital signs.

Results: Among the 267 COVID-19 negative patients, $42.7 \%$ had respiratory, $14.2 \%$ had other infectious, and $11.2 \%$ had cardiovascular diseases. Further, 9.0\% and 6.7\% had oncological and gastroenterological diagnoses, respectively. Compared to COVID-19 negative airway infections, COVID-19 patients showed less dyspnea (OR 0.440; $p=0.024)$ but more dysgeusia (OR 7.631; $p=0.005$ ). Their hospital stay was significantly longer (9.0 vs. 5.6 days; $p=0.014)$, and their mortality significantly higher (OR 3.979; $p=0.014$ ).

Conclusion: For many common ED diagnoses, COVID-19 should be considered a differential diagnosis. COVID-19 cannot be distinguished from COVID-19 negative respiratory infections by clinical signs, symptoms, or laboratory results. When hospitalization is necessary, the clinical course of COVID-19 airway infections seems to be more severe compared to other respiratory infections.

Trial registration: German Clinical Trial Registry DRKS, DRKS-ID of the study: DRKS00021675 date of registration: May 8th, 2020, retrospectively registered.

Keywords: COVID-19, Differential diagnosis, Respiratory infection, Triage, Clinical symptoms, Emergency department, SARS-Cov-2

\footnotetext{
*Correspondence: David.fistera@uk-essen.de

${ }^{1}$ Center of Emergency Medicine, University Hospital Essen,

Hufelandstrasse 55, 45147 Essen, Germany

Full list of author information is available at the end of the article
}

\section{Background}

COVID-19 is an unprecedented situation for society and health care worldwide with more than 211 million cases worldwide and more than 4,400,000 fatalities (Date 08/23/21) [1]. Whereas the majority of infections is mild [2-5] or even asymptomatic [6], about

(C) The Author(s) 2021. Open Access This article is licensed under a Creative Commons Attribution 4.0 International License, which permits use, sharing, adaptation, distribution and reproduction in any medium or format, as long as you give appropriate credit to the original author(s) and the source, provide a link to the Creative Commons licence, and indicate if changes were made. The images or other third party material in this article are included in the article's Creative Commons licence, unless indicated otherwise in a credit line to the material. If material is not included in the article's Creative Commons licence and your intended use is not permitted by statutory regulation or exceeds the permitted use, you will need to obtain permission directly from the copyright holder. To view a copy of this licence, visit http://creativecommons.org/licenses/by/4.0/. The Creative Commons Public Domain Dedication waiver (http://creativeco mmons.org/publicdomain/zero/1.0/) applies to the data made available in this article, unless otherwise stated in a credit line to the data. 
five percent develop a critical disease [5]. Respiratory failure due to severe pneumonia and multiorgan dysfunction with coagulopathy, nephropathy, and affection of the central nervous system cause an estimated case fatality rate at around 0.7 to $2.3 \%[5,7,8]$. Laboratory features that have been associated with worse outcome comprise elevation of C-reactive protein, $\mathrm{D}$-dimer, lactate dehydrogenase, acute kidney injury, and troponin $[9,10]$.

Most patients with mild symptoms can be treated as outpatients, whereas severely ill COVID-19 patients and patients with similar symptoms cross their way in the emergency department (ED). The variety of symptoms is broad and therefore challenging during primary triage, especially to avoid further spread of the infection and to protect staff from infection.

A report of over 370,000 documented symptomatic cases in the U.S. found cough (50\%), fever (43\%), myalgia (36\%), headache (34\%), and dyspnea (29\%) to be the most common symptoms, but diarrhea (19\%), nausea $(12 \%)$ and taste/smell disorders $(<10 \%)$ were also present in a relevant number of cases [11]. Many of these can be found in other common ED diagnoses comprising heart failure, acute coronary syndrome, exacerbation of COPD, and even gastroenterological and oncological diagnoses. Older patients may present with an atypical and therefore misleading clinical picture consisting of falls and malaise [12].

However, a clinical differential diagnosis between COVID-19 and patients presenting with similar symptoms would be very helpful during primary triage.

We, therefore, hypothesized the following:

a) Differential diagnosis of COVID-19 is very broad and not limited to respiratory diseases.

b) There might be specific differences in symptoms or clinical parameters between COVID-19 positive and negative airway infections that may help to distinguish both entities clinically.

c) The clinical course may be more severe in COVID-19 inpatients compared to other infectious airway diseases.

Therefore, we conducted a retrospective analysis of the differential diagnoses of the symptomatic but COVID-19 negative patients in our cohort.

In addition, we tried to identify clinical characteristics and laboratory features that could improve early triage in the ED between patients with proven COVID19 and patients with acute respiratory infections from other origins as a case-control study.

\section{Methods}

The study was conducted following a similar protocol as a previous one [13], so patients and methods show some overlap.

\section{Patients}

We performed a retrospective, single-center case-control study. Patients with possible symptoms of COVID19 presenting at the ED of the University Hospital Essen during the first wave of pandemic between March and April 2020 that underwent SARS-CoV2 testing by nasopharyngeal swab and RT-PCR were included in this analysis.

At least one of the following symptoms was mandatory for inclusion: sore throat, dyspnea, cough, chest pain, fever, fatigue, headache, myalgia, nausea, diarrhea, and dysgeusia.

The study was registered at the German Clinical Trials Registry (Trial number: DRKS00021675, Date: May 8,2020 ). Our study was approved by the institutional ethics committee, and informed consent was waived (Project number: 20-9310-BO).

Patients and the public were not involved in this study.

\section{Methods}

All patients were tested by a SARS-Cov-2 nasopharyngeal swab (ViroCult ${ }^{\circledR}$, Medical Wire \& Equipment Co. Ltd., Corsham, Wiltshire, UK). For detection of SARS$\mathrm{CoV}-2$, an reverse transcription polymerase chain reaction (RT-PCR) (SARS-CoV-2 RT-PCR Kit 1.0, Altona Diagnostics GmbH, Hamburg, Germany) was performed [14]. Computed tomography (CT) pulmonary angiography and additional laboratory testing were performed when symptoms of the lower respiratory tract involvement occurred. Retesting or an additional bronchoscopy could be added in case of negative swab testing and ongoing suspicion. Strict isolation measures were kept until COVID-19 was ruled out.

\section{Parameters}

We analyzed ICD-10 main diagnosis groups of all symptomatic but COVID-19 negative patients. All patients with acute infectious respiratory diseases were included in the main diagnosis group "J" (respiratory diseases). Those with non-infectious diseases (i.e., pleural effusion, exacerbated COPD without acute infection, etc.) were excluded from further analysis (Fig. 1).

Clinical characteristics, Manchester Triage System (MTS) categories, and laboratory parameters were compared and analyzed between patients with positive swab results for SARS-CoV-2 and those with an acute 
COVID19:

Differential diagnosis

Flow chart
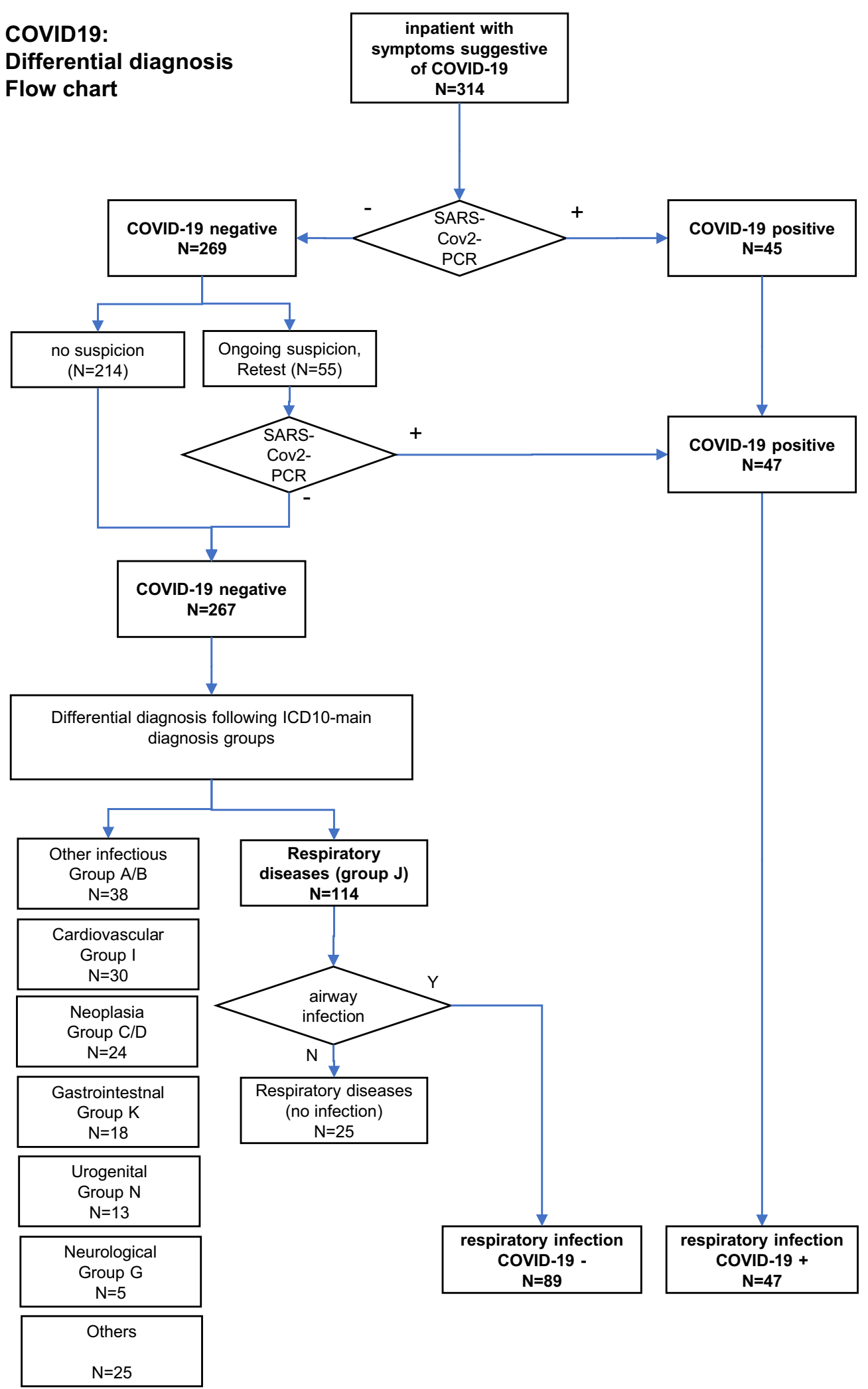

Fig. 1 Flow chart of differential diagnosis 
infectious respiratory disease of other origins, as mentioned above.

Clinical characteristics were symptoms upon ED arrival comprising sore throat, dyspnea, chest pain, cough, fever, fatigue, headache, myalgia, diarrhea, nausea, and dysgeusia.

Laboratory results were white blood cell count, lymphocytes, procalcitonine, C-reactive protein, creatinine, glomerular filtration rate, $\mathrm{D}$-dimers, and troponine.

Patient data were extracted from electronic medical record (ERPath, eHealth-Tec Innovations $\mathrm{GmbH}$, Berlin, Germany; Medico, Cerner Health Services GmbH, Idstein, Germany).

Missing data that could not be extracted from patients' records were excluded from statistical analyses.

\section{Statistical analyses}

Results were reported as mean \pm standard deviations for continuous variables. We used a t-test to evaluate metric data. Data were tested by Levene's test to assess the equality of variances. For unequal variances, a Welch's $\mathrm{t}$-test was performed to analyze metric data.

Results for categorical variables were reported as percentages, calculated adjusted odds ratios (ORs), and 95\% confidence intervals (CIs) and Pearson's $\mathrm{x}^{2}$ test or the Fisher's exact test was used. Statistical significance was defined as two-tailed $p<0.05$. All data were analyzed using SPSS, version 26 (IBM, Armonk, NY, USA).

\section{Results}

A total of 267 SARS-CoV-2 negative patients $(61.8 \%$ male, mean age $65.6 \pm 17.7$ years) were analysed for their ICD main diagnosis group. Respiratory diseases (ICD 10 group J) were found in $42.7 \%(114 / 267)$ of cases, followed by $14.2 \%(38 / 267)$ infections of other origins (ICD 10 groups A/B), 11.2\% (30/267) cardiovascular (ICD 10 group I), 9.0\% (24/267) oncological (ICD 10 groups C/D), $6.7 \%$ (18/267) gastrointestinal (ICD 10 group K), 4.9\% (13/267) urogenital (ICD 10 group N), 1.9\% (5/267) neurological (ICD 10 group G), and 9.4\% (25/267) miscellaneous diseases (all remaining ICD 10 groups; Fig. 2).

Further evaluation of the respiratory diseases group $(n=114)$ resulted in the exclusion of 25 cases of noninfectious respiratory diseases (pulmonary edema, non-infectious exacerbation of COPD, pleural effusion, asthma, and hypercapnic respiratory failure), so a total of 89 COVID-19 negative respiratory infections (50 pneumonia (J18.0-J18.9), 17 influenza/viral pneumonia (J10.0, J10.1, J10.8, J12.1, J12.8), six upper respiratory tract infections (J06.8, J06.9), 16 acute bronchitis (J20.9, J22, J44.01, J44.09)) were included.

A total of 136 patients [mean age: 68 years \pm 17.5 year; 46 female (33.8\%)] were included in the analysis. Baseline

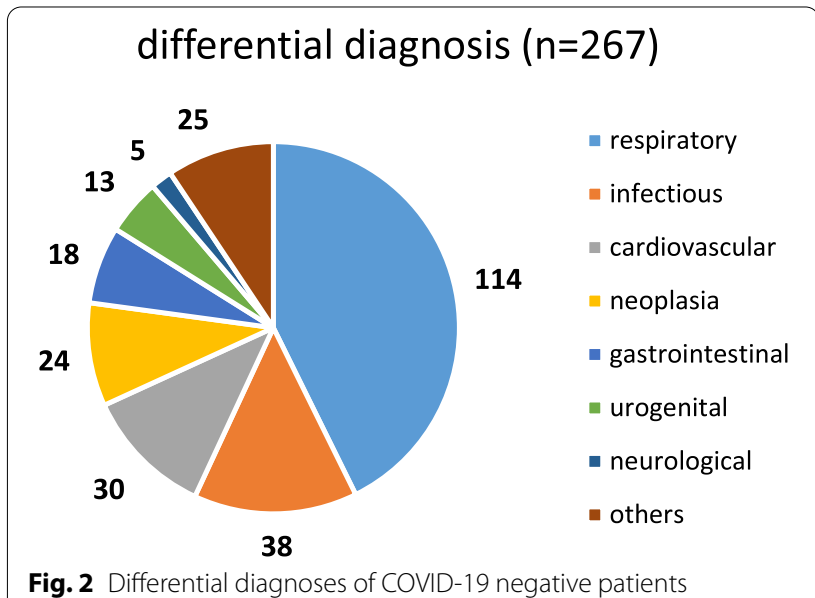

characteristics are summarized in Table 1. According to the MTS, 14 patients were classified as "red" (10.3\%), 12 patients as "orange" (8.8\%), 50 patients as "yellow" (36.8\%), 58 patients as "green" (42.6\%), and two patients as "blue" (1.5\%).

Of all COVID-19 patients, 40\% (19/47) reported dyspnea, while this clinical feature was present in $61 \%(54 / 89)$ of non-COVID-19 patients (OR 0.440; $p=0.024$ ). Among the COVID-19 patients, $15 \%$ reported taste disorders (7/47), whereas only $2 \%(2 / 89)$ of the COVID-19 negative patients did so (OR 7.631; $p=0.005$ ). Significant differences between the two groups were not observed for other clinical features or vital parameters (Table 2).

Except for renal disorders (8.5\% vs. 24,7\%; OR 0.283; $\mathrm{p}=0.025)$, no significant differences were observed for clinical preconditions (cardiac or pulmonary disorders, previous thrombosis or pulmonary embolism, and oncological diseases) between COVID-19 positive and COVID-19 negative patients. The number of active smokers was significantly higher in the COVID-19 negative group $(16.9 \%$ vs. $2.1 \%$; OR $0.107 ; p=0.011)$. However, there was a high number of patients with unknown smoking status in both groups $(70.2 \%$ vs. $58.4 \%$; $p=0.177)$.

COVID-19 inpatients had a significantly higher mortality than the group with pulmonary infections from other origin (19.1\% versus $5.6 \%$; OR $3.979 ; p=0.014$ ).

The duration of hospital stay was longer among COVID-19 patients (9.0 vs. 5.6 days; $p=0.014$ ) than COVID-19 negative patients.

In the group of COVID-19 patients, mean levels of lactate dehydrogenase (LDH) were significantly higher ( 439.5 vs. $335.8 \mathrm{U} / \mathrm{L} ; p=0.025$ ). The mean procalcitonine levels tended to be higher in COVID-19 negative patients $(6.74 \mathrm{vs} .0 .42 \mu \mathrm{g} / \mathrm{L})$ but were not significantly different $(p=0.354)$. 
Table 1 Characteristics of inpatients with airway infections

\begin{tabular}{|c|c|c|c|c|c|}
\hline & $\begin{array}{l}\text { All } \\
(n=136)\end{array}$ & $\begin{array}{l}\text { COVID19+ } \\
(n=47)\end{array}$ & $\begin{array}{l}\text { COVID19- } \\
(n=89)\end{array}$ & $\begin{array}{l}\text { Odds ratio } \\
\text { (95\% confidence interval) }\end{array}$ & $p$-value \\
\hline Age, mean $( \pm S D$, range $)$ & $68( \pm 17.54,23-97)$ & $70( \pm 17.65,23-94)$ & $67( \pm 17.51,24-97)$ & & 0.420 \\
\hline Male gender, n (\%) & $90(66.2)$ & $31(66.0)$ & $59(66.3)$ & $0.985(0.481-2.141)$ & 0.969 \\
\hline \multicolumn{6}{|l|}{ Manchester triage, n (\%) } \\
\hline Red & $14(10.3)$ & $4(8.5)$ & $10(11.2)$ & $0.735(0.217-2.483)$ & 0.619 \\
\hline Orange & $12(8.8)$ & $3(6.4)$ & $9(10.1)$ & $0.606(0.156-2.355)$ & 0.466 \\
\hline Yellow & $50(36.8)$ & $15(31.9)$ & $35(39.3)$ & $0.723(0.343-1.525)$ & 0.394 \\
\hline Green & $58(42.6)$ & $25(53.2)$ & $33(37.1)$ & $1.928(0.942-3.948)$ & 0.071 \\
\hline Blue & $2(1.5)$ & $0(0)$ & $2(2.2)$ & $0.987(0.947-1.009)$ & 0.301 \\
\hline \multicolumn{6}{|c|}{ Medical history, positive for, n (\%) } \\
\hline Cardiac & $85(62.5)$ & $29(61.7)$ & $56(62.9)$ & $0.904(0.436-1.877)$ & 0.769 \\
\hline Pulmonary & $44(32.4)$ & $10(21.3)$ & $34(38.2)$ & $0.429(0.189-0.973)$ & 0.108 \\
\hline PE/thrombosis & $9(6.6)$ & $2(4.3)$ & $7(7.9)$ & $0.53(0.106-2.673)$ & 0.437 \\
\hline Renal & $26(2.9)$ & $4(8.5)$ & $22(24.7)$ & $0.283(0.091-0.879)$ & 0.025 \\
\hline Cancer & $31(22.8)$ & $10(21.3)$ & $21(23.6)$ & $0.87(0.373-2.053)$ & 0.808 \\
\hline \multicolumn{6}{|l|}{ Smoker, n (\%) } \\
\hline Never & $26(19.1)$ & $9(19.1)$ & $17(19.1)$ & $0.997(0.406-2.448)$ & 0.995 \\
\hline Yes & $16(11.8)$ & $1(2.1)$ & $15(16.9)$ & $0.107(0.014-0.839)$ & 0.011 \\
\hline Quitted & $9(6.6)$ & $4(8.5)$ & $5(5.6)$ & $0.640(0.163-2.506)$ & 0.519 \\
\hline Unknown & $85(62.5)$ & $33(70.2)$ & $52(58.4)$ & $0.596(0.281-1.267)$ & 0.177 \\
\hline
\end{tabular}

Bold values mark a significant parameter $(p<0,05)$ and were used to improve readibility and to emphasize main results

All remaining laboratory values, vital parameters, and treatment modes were similar between the two groups (Table 2).

Of the initially 269 SARS-CoV-2 negative patients, 55 had been retested for ongoing clinical suspicion of COVID-19, 14 of these by PCR from bronchoalveolar fluid (BAL). Two of the retested ones revealed to be positive during retesting.

\section{Discussion}

Early triage and differential diagnosis of patients presenting with typical clinical symptoms of COVID-19 remain very challenging but relevant. Our study had the following main findings:

1. Differential diagnosis of typical COVID-19 symptoms is very broad and comprises many common respiratory, infectious, and cardiovascular diseases, whereas respiratory diseases are the most frequent. Diseases from nearly every field of clinical medicine can mimic a clinical picture like that of COVID-19, with respiratory diseases being the most prevalent. Older patients may be even more challenging since the clinical picture may be atypical with syncope and malaise [12].

2. Patients with COVID-19 present with similar symptoms as COVID-19 negative respiratory infections, so clinical discrimination is not reliable. Dyspnea is less frequently found in our COVID-19 patients, whereas dysgeusia is significantly more prevalent. The latter finding has been described by other studies before and can be found in up to $44 \%$ of cases following meta-analyses [15]. Whenever present, dysgeusia should raise high suspicion for COVID-19, especially during a pandemic. Dyspnea is a typical symptom of COVID-19, which could be found in about $29 \%$ of cases in a study of 270,000 patients in the U.S. [11]. Controversially, several authors described a specific phenomenon called "happy hypoxemia" in COVID19 with a disconnect between the severity of hypoxemia and relatively mild respiratory discomfort $[16$, 17]. Therefore, dyspnea might be less frequent in our COVID-19 positive patients than in other respiratory infections. Elevated levels of LDH have been described before [18] and were significantly higher among non-survivors in a case series from Wuhan [10] so this finding in our COVID-19 patients is in line with the more severe clinical course of this group. The tendency towards higher procalcitonine levels in COVID-19 negative patients may be explained by a higher rate of bacterial infections, such as pneumonia, since elevated procalcitonine levels can usually only be found in advanced, respectively complicated courses of COVID-19 [4]. Case numbers might have 
Table 2 Group comparison COVID-19 versus COVID-19 negative airway infections

\begin{tabular}{|c|c|c|c|c|c|}
\hline & $\begin{array}{l}\text { All } \\
(n=136)\end{array}$ & COVID19+ $(n=47)$ & $\begin{array}{l}\text { COVID19- } \\
(\mathrm{n}=89)\end{array}$ & $\begin{array}{l}\text { Odds ratio } \\
\text { ( } 95 \% \text { confidence interval) }\end{array}$ & $p$-value \\
\hline \multicolumn{6}{|l|}{ Symptoms, n (\%) } \\
\hline Dyspnoe & $73(53.7)$ & $19(40.4)$ & $54(60.7)$ & $0.440(0.214-0.905)$ & 0.024 \\
\hline Sore throat & $10(7.4)$ & $4(8.5)$ & $6(6.7)$ & $1.287(0.345-4.806)$ & 0.707 \\
\hline Cough & $79(58.0)$ & $25(28.1)$ & $54(60.7)$ & $0.737(0.361-1.503)$ & 0.400 \\
\hline Fever & $85(62.5)$ & $31(66.0)$ & $54(60.7)$ & $1.256(0.600-2.627)$ & 0.545 \\
\hline Headache & $14(10.3)$ & $5(10.6)$ & $9(10.1)$ & $1.058(0.333-3.360)$ & 0.924 \\
\hline Fatigue & $68(50.0)$ & $22(46.8)$ & $46(51.7)$ & $0.823(0.405-1.670)$ & 0.589 \\
\hline Myalgia & $24(17.6)$ & $6(12.8)$ & $18(20.2)$ & $0.577(0.212-1.570)$ & 0.278 \\
\hline Chest pain & $11(8.1)$ & $2(4.3)$ & $9(10.1)$ & $0.395(0.82-1.909)$ & 0.234 \\
\hline Nausea & $22(16.2)$ & $6(12.8)$ & $16(18.0)$ & $0.668(0.242-1.839)$ & 0.433 \\
\hline Diarrhea & $35(26.5)$ & $13(27.7)$ & $22(24.7)$ & $1.164(0.523-2.592)$ & 0.709 \\
\hline Dysgeusia & $9(6.6)$ & $7(14.9)$ & $2(2.2)$ & $7.631(1.513-38.292)$ & 0.005 \\
\hline Death, n (\%) & $14(10.3)$ & $9(19.1)$ & $5(5.6)$ & $3.979(1.242-12.673)$ & 0.014 \\
\hline \multicolumn{6}{|l|}{ Treatment, n (\%) } \\
\hline $\mathrm{O}_{2}$-therapy & $52(38.2)$ & $20(42.6)$ & $32(36.0)$ & $1.319(0.641-2.717)$ & 0.451 \\
\hline Ventilator & $2(1.4)$ & $0(0.0)$ & $2(2.2)$ & $0.978(0.947-1.009)$ & 0.137 \\
\hline Intensive care & $24(17.6)$ & $6(12.8)$ & $18(20.2)$ & $0.577(0.212-1.570)$ & 0.278 \\
\hline Intermediate care & $12(8.8)$ & $4(8.5)$ & $8(9.0)$ & $0.942(0.268-3.307)$ & 0.926 \\
\hline Time of admission (days) & $6.8( \pm 6.4)$ & $9.0( \pm 8.1)$ & $5.6( \pm 5.0)$ & & 0.014 \\
\hline \multicolumn{6}{|l|}{ Vital parameters } \\
\hline Respiratory rate/min ( \pm SD) & $37.2( \pm 1.2)$ & $23.7( \pm 7.4)$ & $22.3( \pm 6.7)$ & & 0.283 \\
\hline Heart rate/min $( \pm S D)$ & $96.7( \pm 21.6)$ & $93.7( \pm 16.6)$ & $98.4( \pm 23.8)$ & & 0.235 \\
\hline Saturation, $\mathrm{O}_{2}$ in \% ( $\left.\pm \mathrm{SD}\right)$ & $94.3( \pm 7.1)$ & $94.9( \pm 4.0)$ & $94.0( \pm 8.4)$ & & 0.456 \\
\hline Temperature in ${ }^{\circ} \mathrm{C},( \pm \mathrm{SD})$ & $37.2( \pm 1.2)$ & $37.3( \pm 1.0)$ & $37.2( \pm 1.2)$ & & 0.552 \\
\hline BP systolic in mmHg ( \pm SD) & $132.5( \pm 25.6)$ & $136.2( \pm 24.1)$ & $130.52( \pm 26.3)$ & & 0.219 \\
\hline BP diastolic in mmHg $( \pm S D)$ & $79.0( \pm 17.4)$ & $82.9( \pm 18.1)$ & $77.0( \pm 16.7)$ & & 0.057 \\
\hline \multicolumn{6}{|l|}{ Laboratory values } \\
\hline C-reactive proteine, mg/L & $9.57( \pm 7.86)$ & $8.2( \pm 5.8)$ & $10.3( \pm 8.7)$ & & 0.100 \\
\hline Procalcitonine, $\mu \mathrm{g} / \mathrm{L}( \pm \mathrm{SD})$ & $4.53( \pm 36.75)$ & $0.42( \pm 1.49)$ & $6.74( \pm 45.47)$ & & 0.354 \\
\hline Troponin I, $\mu \mathrm{g} / \mathrm{L}( \pm \mathrm{SD})$ & $73.27( \pm 268.64)$ & $76.59( \pm 278.7)$ & $71.33( \pm 265.0)$ & & 0.928 \\
\hline $\mathrm{LDH}, \mathrm{U} / \mathrm{L}( \pm \mathrm{SD})$ & $370.67( \pm 248.34)$ & $439.5( \pm 264.9)$ & $335.8( \pm 233.4)$ & & 0.025 \\
\hline Creatinine, mg/dL ( $\pm \mathrm{SD}$ ) & $1.21( \pm 0.87)$ & $1.18( \pm 0.90)$ & $1.23( \pm 0.86)$ & & 0.729 \\
\hline $\mathrm{GFR}, \mathrm{mL} / \mathrm{min}( \pm \mathrm{SD})$ & $58.10( \pm 19.10)$ & $58.7( \pm 19.18)$ & $57.8( \pm 19.17)$ & & 0.805 \\
\hline D-dimer, mg/L ( $\pm S D)$ & $3.10( \pm 6.13)$ & $4.29( \pm 7.95)$ & $2.44( \pm 0.61)$ & & 0.222 \\
\hline $\mathrm{WBC} / \mathrm{mm}^{3}( \pm \mathrm{SD})$ & $12.04( \pm 21.44)$ & $8.00( \pm 4.11)$ & $14.1( \pm 26.04)$ & & 0.115 \\
\hline Lymphocytes $/ \mathrm{mm}^{3}( \pm \mathrm{SD})$ & $2.39( \pm 10.99)$ & $1.20( \pm 1.40)$ & $3.1( \pm 13.95)$ & & 0.322 \\
\hline
\end{tabular}

Bold values mark a significant parameter $(p<0,05)$ and were used to improve readibility and to emphasize main results

been too small to reach significance here. The significantly lower frequency of smokers in the COVID-19 group should be interpreted cautiously since the rate of unknown smoking status is $70 \%$, thwarting the attempt to draw any further conclusions. Therefore, no clinical sign or symptom nor any of the analyzed laboratory values will be able to predict COVID-19 status in a reliable way. However, dysgeusia, when present, should raise a high suspicion of COVID19 during a pandemic. A strict isolation policy and frequent SARS-CoV-2 testing will remain the most important measures to keep control of the situation.

3. When inpatient treatment for respiratory infections is needed, COVID-19 patients seem to take a more severe clinical course. The mortality of our COVID19 positive inpatient patients is significantly higher than in the COVID-19 negative group. The mortality rate of $19.1 \%$ is comparable to those found by Petrilli et al. [19], who reported mortality of $24.1 \%$ among inpatients in New York City. The COVID negative 
group is a heterogeneous one, comprising different kinds of respiratory infections with pneumonia as the most frequent diagnosis (50/89). Inpatients with CAP showed 30 -day mortality of $11.9 \%$ in Europe in one study [20], so the lower mortality of the COVID negative group might be explainable hereby. This finding is supported by a study that described a more severe course of COVID-19 than Influenza during the first wave in the Toronto area [21]. A more severe course of the disease can also explain the significantly longer length of hospital stay (9.0 vs. 5.6 days; $p=0.014$ ) among the COVID-19 positive patients in our study. Notably, bacterial or fungal superinfections seem to occur seldom in the course of COVID-19 [22].

4. The false-negative rate of nasopharyngeal swab testing was low, and 55 patients were retested due to ongoing clinical suspicion of COVID-19, some even more than one time including bronchoalveolar specimens in 14 cases. Only two more positive cases (3.6\%) could be found, both by BAL. This suggests that the false-negative rate is low whenever experienced and well-trained staff carries out a nasopharyngeal SARS-Cov2 swab. Previous research has reported rates of $11 \%$ for false-negative PCR results in COVID-19 [23]. Of note, all patients were symptomatic, so those in the very early stages of disease who might carry a higher likelihood of false-negative testing were scarce in our study.

\section{Limitations}

Due to retrospective data collection, selection bias and errors in data entry could not be completely excluded.

A standardized form on symptoms was established in the electronic record; however, completeness of medical history and clinical complaints cannot be guaranteed. This study is a single-center study, and for this reason, data should not be generalized. Since the first wave of COVID-19 had been controlled early in Germany, the sample size is limited.

Further, we included only patients admitted to our $E D$, whereas the number of outpatient treatment may be higher in COVID-19 than in non-COVID-19 respiratory infections.

In our cohort, the number of patients with unknown smoking status is very high (62.5\%). Therefore, influence of smoking on outcome should be interpreted very cautious.

\section{Conclusions}

Differential diagnoses of COVID-19 are plentiful and comprise many common diseases, most notably ailments associated with respiratory impairment. Triage remains challenging in the emergency department since there are no reliable clinical or laboratory parameters to distinguish safely between COVID-19 and airway infections of other origins. When inpatient, COVID-19 takes a more severe clinical course than comparable COVID-19 negative airway infections. Therefore, a strict isolation policy together with broad and rapid testing will remain the most important measures for the months to come.

\section{Abbreviations \\ BAL: Bronchoalveolar lavage; CAP: Community-acquired pneumonia; COPD: Chronic obstructive pulmonary disease; COVID-19: Coronavirus disease subtype 2019; CT: Computed tomography; ED: Emergency department; ICD: International code (of) diagnosis; MTS: Manchester triage scale; NSTEMI: Non- ST segment elevation myocardial infarction; PCR: Polymerase chain reaction; SARS-Cov2: Severe acute respiratory syndrome coronavirus 2.}

\section{Acknowledgements}

We thank all emergency department employees for their great support during hard times.

\section{Authors' contributions}

$D F, D P, A H, B M S, L U, C H$, and JR contributed to data acquisition. DF, DP, AH, and CK contributed to data analysis. DF, DP, JR, and BMS interpreted data. DF, DP, $A H, B M S, L U, C H, S D, C K, J R, R M$, and CT drafted the article and substantially revised it. All authors read and approved the final manuscript.

Funding

Open Access funding enabled and organized by Projekt DEAL.

\section{Availability of data and materials}

The anonymized dataset supporting these conclusions is available upon reasonable request from the corresponding author.

\section{Declarations}

\section{Ethics approval and consent to participate}

Our study was approved by the institutional ethics committee of the University Essen-Duisburg, and informed consent was waived (File number: 20-9310-BO, Date: May 6, 2020). The study was registered at the German Clinical Trials Registry (Trial number: DRKS00021675, Date: May 8, 2020). Patients and the public were not involved in this study.

\section{Consent for publication}

Not applicable.

\section{Competing interests}

The authors state they have no competing interests.

\section{Author details}

${ }^{1}$ Center of Emergency Medicine, University Hospital Essen, Hufelandstrasse 55, 45147 Essen, Germany. ${ }^{2}$ Department of Pulmonary Medicine, University Medicine Essen - Ruhrlandklinik, Essen, Germany. ${ }^{3}$ Department of Infectious Diseases, West German Center of Infectious Diseases, University Hospital Essen, University Duisburg-Essen, Essen, Germany. ${ }^{4}$ Department of Diagnostic and Interventional Radiology and Neuroradiology, University Hospital Essen, Essen, Germany.

Received: 13 November 2020 Accepted: 7 September 2021

Published online: 17 September 2021 


\section{References}

1. WHO. Coronavirus disease (COVID-2019) situation reports $2020 \mathrm{https}: / /$ www.who.int/docs/default-source/coronaviruse/situation-reports/20200 607-covid-19-sitrep-139.pdf?sfvrsn=79dc6d08_2

2. Bajema KL, Oster AM, McGovern OL, Lindstrom S, Stenger MR, Anderson TC, et al. Persons evaluated for 2019 novel coronavirus - United States, January 2020. MMWR Morb Mortal Wkly Rep. 2020;69(6):166-70.

3. Chan JF, Yuan S, Kok KH, To KK, Chu H, Yang J, et al. A familial cluster of pneumonia associated with the 2019 novel coronavirus indicating person-to-person transmission: a study of a family cluster. Lancet. 2020;395(10223):514-23.

4. Wang D, Hu B, Hu C, Zhu F, Liu X, Zhang J, et al. Clinical characteristics of 138 hospitalized patients with 2019 novel coronavirus-infected pneumonia in Wuhan, China. JAMA. 2020;323(11):1061-9.

5. Wu Z, McGoogan JM. Characteristics of and important lessons from the coronavirus disease 2019 (COVID-19) outbreak in China: summary of a report of 72314 cases from the Chinese Center for Disease Control and Prevention. JAMA. 2020;323(13):1239-42.

6. Oran DP, Topol EJ. Prevalence of asymptomatic SARS-CoV-2 infection: a narrative review. Ann Intern Med. 2020;173(5):362-7.

7. Guan W-J, Ni Z-Y, Hu Y, Liang W-H, Ou C-Q, He J-X, et al. Clinical characteristics of coronavirus disease 2019 in China. N Engl J Med. 2020;382(18):1708-20.

8. Wichmann D, Sperhake J-P, Lütgehetmann M, Steurer S, Edler C, Heinemann A, et al. Autopsy findings and venous thromboembolism in patients with COVID-19. Ann Intern Med. 2020;173:268-77.

9. Wu C, Chen X, Cai Y, Ja X, Zhou X, Xu S, et al. Risk factors associated with acute respiratory distress syndrome and death in patients with coronavirus disease 2019 pneumonia in Wuhan, China. JAMA Internal Med. 2019;2020(180):934-43

10. Zhou F, Yu T, Du R, Fan G, Liu Y, Liu Z, et al. Clinical course and risk factors for mortality of adult inpatients with COVID-19 in Wuhan, China: a retrospective cohort study. Lancet. 2020;395(10229):1054-62.

11. Stokes EK, Zambrano LD, Anderson KN, Marder EP, Raz KM, El Burai FS, et al. Coronavirus disease 2019 case surveillance - United States, January 22-May 30, 2020. MMWR Morb Mortal Wkly Rep. 2020;69(24):759-65.

12. Annweiler C, Sacco G, Salles N, Aquino JP, Gautier J, Berrut G, et al. National French Survey of Coronavirus Disease (COVID-19) symptoms in people aged 70 and over. Clin Infect Dis. 2021;72(3):490-4.

13. Fistera D, Pabst D, Hartl A, Schaarschmidt BM, Umutlu L, Dolff S, et al. Separating the wheat from the chaff-COVID-19 in a German emergency department: a case-control study. Int J Emerg Med. 2020;13(1):44.
14. Corman VM, Landt O, Kaiser M, Molenkamp R, Meijer A, Chu DK, et al. Detection of 2019 novel coronavirus (2019-nCoV) by real-time RT-PCR. Eurosurveillance. 2020;25(3):2000045.

15. Tong JY, Wong A, Zhu D, Fastenberg JH, Tham T. The prevalence of olfactory and gustatory dysfunction in COVID-19 patients: a systematic review and meta-analysis. Otolaryngol Head Neck Surg. 2020;163(1):3-11.

16. Allali G, Marti C, Grosgurin O, Morelot-Panzini C, Similowski T, Adler D. Dyspnea: the vanished warning symptom of COVID-19 pneumonia. J Med Virol. 2020. https://doi.org/10.1002/jmv.26172.

17. Dhont S, Derom E, Van Braeckel E, Depuydt P, Lambrecht BN. The pathophysiology of "happy" hypoxemia in COVID-19. Respir Res. 2020;21(1):198.

18. Goyal P, Choi JJ, Pinheiro LC, Schenck EJ, Chen R, Jabri A, et al. Clinical characteristics of covid-19 in New York City. N Engl J Med. 2020:382(24):2372-4.

19. Petrilli CM, Jones SA, Yang J, Rajagopalan H, O'Donnell L, Chernyak Y, et al Factors associated with hospital admission and critical illness among 5279 people with coronavirus disease 2019 in New York City: prospective cohort study, BMJ. 2020:369:m1966

20. Arnold FW, Wiemken TL, Peyrani P, Ramirez JA, Brock GN. Mortality differences among hospitalized patients with community-acquired pneumonia in three world regions: results from the Community-Acquired Pneumonia Organization (CAPO) International Cohort Study. Respir Med. 2013;107(7):1101-11.

21. Verma AA, Hora T, Jung HY, Fralick M, Malecki SL, Lapointe-Shaw L, et al. Characteristics and outcomes of hospital admissions for COVID-19 and influenza in the Toronto area. CMAJ. 2021;193(12):E410-8.

22. Kubin CJ, McConville TH, Dietz D, Zucker J, May M, Nelson B, et al. Characterization of bacterial and fungal infections in hospitalized patients with coronavirus disease 2019 and factors Associated With Health Care-Associated Infections. Open Forum Infect Dis. 2021;8(6):ofab201.

23. Lee TH, Lin RJ, Lin RTP, Barkham T, Rao P, Leo YS, et al. Testing for SARSCoV-2: can we stop at two? Clin Infect Dis. 2020;71:2246-8.

\section{Publisher's Note}

Springer Nature remains neutral with regard to jurisdictional claims in published maps and institutional affiliations.
Ready to submit your research? Choose BMC and benefit from:

- fast, convenient online submission

- thorough peer review by experienced researchers in your field

- rapid publication on acceptance

- support for research data, including large and complex data types

- gold Open Access which fosters wider collaboration and increased citations

- maximum visibility for your research: over 100M website views per year

At BMC, research is always in progress.

Learn more biomedcentral.com/submissions 